\title{
A lanthanide-titanium oxo cluster-polymer composite: From clusters to fluorescent ink
}

\author{
Yongkai Deng ${ }^{1}$, Xin Zheng ${ }^{2}$, Hao Zheng ${ }^{1}$, Han Xu ${ }^{1}$, Fushan $\mathrm{Li}^{{ }^{2}}$, Lasheng Long ${ }^{{ }^{*}}$ and Lansun Zheng ${ }^{1}$
}

Fluorescent ink has become an effective anti-counterfeiting material to prevent counterfeiters from making and selling fake products [1-4]. From its practical application, an ideal fluorescent ink should be environmentally friendly, have high stability and good viscosity, and exhibit excellent luminescent performance. To obtain such fluorescent inks, different fluorescent materials, such as carbon dots [5-7], lanthanide-doped compounds [8-10], inorganic semiconductor complexes [11-13], organic dyes [14-16], metal-organic frameworks [17-19], lanthanide coordination compounds [20,21] and cluster compounds [22,23], have been used to prepare fluorescent inks. Although these fluorescent materials have their own advantages as fluorescent inks, they also have their own disadvantages. For example, organic dyes used as fluorescent inks often encounter the problems of aggregation-induced quenching and small Stokes shifts [14-16], while carbon dots suffer from unclear structures, and concerns about the reproducibility of carbon dots have affected their widespread use $[5,6]$. Therefore, it is necessary to develop fluorescent ink with excellent performance.

Lanthanide-titanium oxo clusters (LTOCs) are regarded as promising luminescent materials. The formation of $\mathrm{Ln}-\mathrm{Ti}-\mathrm{O}$ species can not only effectively increase the rigidity of LTOCs, but also greatly reduce the energy required for $\mathrm{Ln}^{3+}$ photoluminescence sensitization [24-26]. Additionally, their structural stability and luminescence performance can be greatly improved by introducing strongly electron-donating carboxylic acid ligands into LTOCs $[27,28]$. However, the poor solubility and film-forming properties of LTOCs make them difficult to use directly as fluorescent inks. In previous work, we have demonstrated that the preparation of LTOC-polymer composites (LTOCPs) through covalently linking LTOCs to polymers can effectively improve the mechanical properties of the LTOCs, without noticeably changing their luminescent performance [29]. Distinctly, if the LTOCs in the LTOCPs display excellent luminescent properties, the LTOCPs as fluorescent ink exhibit excellent performance. Along this line, we use aminocontaining LTOCs of $\mathrm{Eu}_{2} \mathrm{Ti}_{4}-\mathrm{NH}_{2} \quad\left(\mathrm{Eu}_{2} \mathrm{Ti}_{4}-\mathrm{NH}_{2}=\right.$ $\left[\mathrm{Eu}_{2} \mathrm{Ti}_{4}\left(\mu_{2}-\mathrm{O}\right)_{2}\left(\mu_{3}-\mathrm{O}\right)_{4}(\text { phen })_{2}(\text { tbza })_{9}(\right.$ paza $\left.)\right] \cdot 8 \mathrm{H}_{2} \mathrm{O}$ Htbza = 4-tert-butylbenzoic acid, Hpaza = 4-aminobenzoate acid, phen $=1,10$-phenanthroline) and PEG $(\mathrm{PEG}=$ methoxy-poly (ethylene glycol) succinimidyl carbonate, $2000 \mathrm{~g} \mathrm{~mol}^{-1}$ ) to prepare the LTOCP of $\mathrm{Eu}_{2} \mathrm{Ti}_{4}-\mathrm{NH}_{2} @ \mathrm{PEG}$ (2) through an amidation reaction activated by $N$-hydroxy succinimide (NHS). Significantly, 2 not only exhibits excellent fluorescent properties, but also has good solubility in a wider range of solvents and excellent film-forming properties.

Cluster 1 was prepared through solvothermal reaction of 4-tert-butylbenzoate (Htbza, $0.36 \mathrm{mmol}, 64 \mathrm{mg}$ ), 4aminobenzoic acid (Hpaza, $0.04 \mathrm{mmol}, 6 \mathrm{mg}$ ), $\mathrm{Eu}(\mathrm{OAc})_{3} \cdot 4 \mathrm{H}_{2} \mathrm{O}(0.065 \mathrm{mmol}, 26 \mathrm{mg}), 1,10$-phenanthroline monohydrate (phen, $0.1 \mathrm{mmol}, 20 \mathrm{mg})$ and $\mathrm{Ti}\left(\mathrm{O}^{\mathrm{i}} \mathrm{Pr}\right)_{4}$ $(0.08 \mathrm{mmol}, 24 \mu \mathrm{L})$. The purity of bulk sample 1 was demonstrated by the similarity between experimental powder X-ray diffraction (PXRD) patterns and simulated patterns (Fig. S1). Single-crystal XRD shows that the $\mathrm{Eu}_{2} \mathrm{Ti}_{4}-\mathrm{NH}_{2}$ cluster belongs to the monoclinic crystal $P 2_{1} / c$ space group and consists of two $\mathrm{Eu}^{3+}$, four $\mathrm{Ti}^{4+}$, two $\mu_{2}-\mathrm{O}$, four $\mu_{3}-\mathrm{O}$, two phen, nine tbza ${ }^{-}$, one paza ${ }^{-}$and four $\mathrm{CH}_{3} \mathrm{CN}$ (Table S1). Structurally, the cluster core of the $\left[\mathrm{Eu}_{2} \mathrm{Ti}_{4} \mathrm{O}_{6}\right]^{10+}$ in $\mathbf{1}$ is the same as that reported previously in the cluster of $\operatorname{Eu}_{2} \mathrm{Ti}_{4}\left(\mu_{2}-\mathrm{O}\right)_{2}\left(\mu_{3}-\mathrm{O}\right)_{4}(\text { phen })_{2}(\text { tbza })_{10}$. $4 \mathrm{CH}_{3} \mathrm{CN}$ [30], that is, each $\mathrm{Eu}^{3+}$ connects to two $\mathrm{Ti}^{4+}$ ions through one $\mu_{3}-\mathrm{O}$, forming a triangular $\left[\mathrm{EuTi}_{2}\left(\mu_{3}-\mathrm{O}\right)\right]^{9+}$ unit, which is further connected by a pair of $\mu_{2}-\mathrm{O}$ and $\mu_{3}$ -

${ }^{1}$ Collaborative Innovation Center of Chemistry for Energy Materials, State Key Laboratory of Physical Chemistry of Solid Surfaces, Department of Chemistry, College of Chemistry and Chemical Engineering, Xiamen University, Xiamen 361005, China

${ }^{2}$ Institute of Optoelectronic Technology, Fuzhou University, Fuzhou 350116, China

* Corresponding authors (emails: 1slong@xmu.edu.cn (Long L); fsli@fzu.edu.cn (Li F)) 
$\mathrm{O}$ bridges to generate a cluster core of $\left[\mathrm{Eu}_{2} \mathrm{Ti}_{4} \mathrm{O}_{6}\right]^{10+}$. Among the six metal atoms in the cluster core of $\left[\mathrm{Eu}_{2}-\right.$ $\left.\mathrm{Ti}_{4} \mathrm{O}_{6}\right]^{10+}$, four $\mathrm{Ti}^{4+}$ ions form a parallelogram, and two $\mathrm{Eu}^{3+}$ are located on either side of the parallelogram (Fig. 1a). Solidifying the cluster core of $\left[\mathrm{Eu}_{2} \mathrm{Ti}_{4} \mathrm{O}_{6}\right]^{10+}$ by two phen ligands, nine tbza ligands and one paza ligand generates 1 (Fig. 1b). Each $\mathrm{Eu}^{3+}$ ion is coordinated by two $\mathrm{N}$ atoms from one $o$-phenanthroline ligand, four $\mathrm{O}$ atoms from four benzoic acid ligands and two $\mu_{3}$-O atoms in a distorted triangular dodecahedral geometry. Each $\mathrm{Ti}^{4+}$ ion is coordinated by two $\mu_{3}-\mathrm{O}$, one $\mu_{2}-\mathrm{O}$, and three $\mathrm{O}$ from three different benzoic acid ligands in a distorted octachedral geometry. Guest acetonitrile molecules are within the gaps of the cluster molecules through $\mathrm{C}-\mathrm{H} \cdots \mathrm{O}$ interactions (Fig. 1c). The Ti-O and $\mathrm{Eu}-\mathrm{O}$ bond distances are $1.817(3)-2.114(3) \AA$ and $2.334(2)-2.426(3) \AA$, respectively. The Eu-N bond distances are 2.540(3)2.635(4) $\AA$ (Table S2). The bond distances of Ti-O, $\mathrm{Eu}-\mathrm{O}$ and $\mathrm{Eu}-\mathrm{N}$ are comparable to those reported in $\mathrm{Eu}_{2} \mathrm{Ti}_{4}\left(\mu_{2}-\mathrm{O}\right)_{2}\left(\mu_{3}-\mathrm{O}\right)_{4}(\text { phen })_{2}(\mathrm{tbza})_{10} \cdot 4 \mathrm{CH}_{3} \mathrm{CN} \quad$ [30]. Although single-crystal structural analysis reveals that there are four guest acetonitrile molecules in 1, both the elemental (Supplementary information) and thermogravimetric (TG) analyses (Fig. S2) indicate that there are eight guest $\mathrm{H}_{2} \mathrm{O}$ molecules in $\mathbf{1}$. This discrepancy is due to the guest acetonitrile molecules between the clusters being easily lost at room temperature.

Because 1 contains a paza ${ }^{-}$ligand, an amidation reaction activated by $\mathrm{N}$-hydroxysuccinimide (NHS) was performed through the reaction of $\mathbf{1}$ with PEG in toluene solution. Finishing the crosslink reaction between the amine group of $\mathbf{1}$ and succinimidyl carbonate group of PEG generates the powder of 2 . Fig. 2 illustrates the ${ }^{1} \mathrm{H}$ nuclear magnetic resonance $\left({ }^{1} \mathrm{H}\right.$ NMR) spectra of $\mathbf{1}, \mathbf{2}$, and PEG. The chemical shift peaks of the aromatic group (7-9 ppm) and tert-butyl (1.3 ppm) in the spectrum of 1 and the chemical shift signals of the $\mathrm{CH}_{2}-\mathrm{CH}_{2}-\mathrm{O}-$ (3.6 ppm) in PEG appeared in the spectrum of 2; in particular, the chemical signal for the proton of the $\mathrm{NH}_{2}$ group (4.7 ppm) in $\mathbf{1}$ completely disappeared in the spectrum of 2, distinctly indicating that the amino group in paza ${ }^{-}$in $\mathbf{1}$ completely reacted with PEG through NHS activation.

To demonstrate the integrity of $\mathbf{1}$ in $\mathbf{2}$, energy dispersive X-ray spectroscopy (EDS) and element mapping were conducted in $\mathbf{2}$ (Fig. S3). The element mapping of $\mathbf{2}$ indicates that both the europium and titanium in $\mathbf{2}$ are uniformly distributed. The EDS result reveals that the Eu/ $\mathrm{Ti}$ atomic ratio in 2 is $1 / 1.94$. This value is very close to the $2 / 4$ ratio obtained from the crystal structure of $\mathbf{1}$.
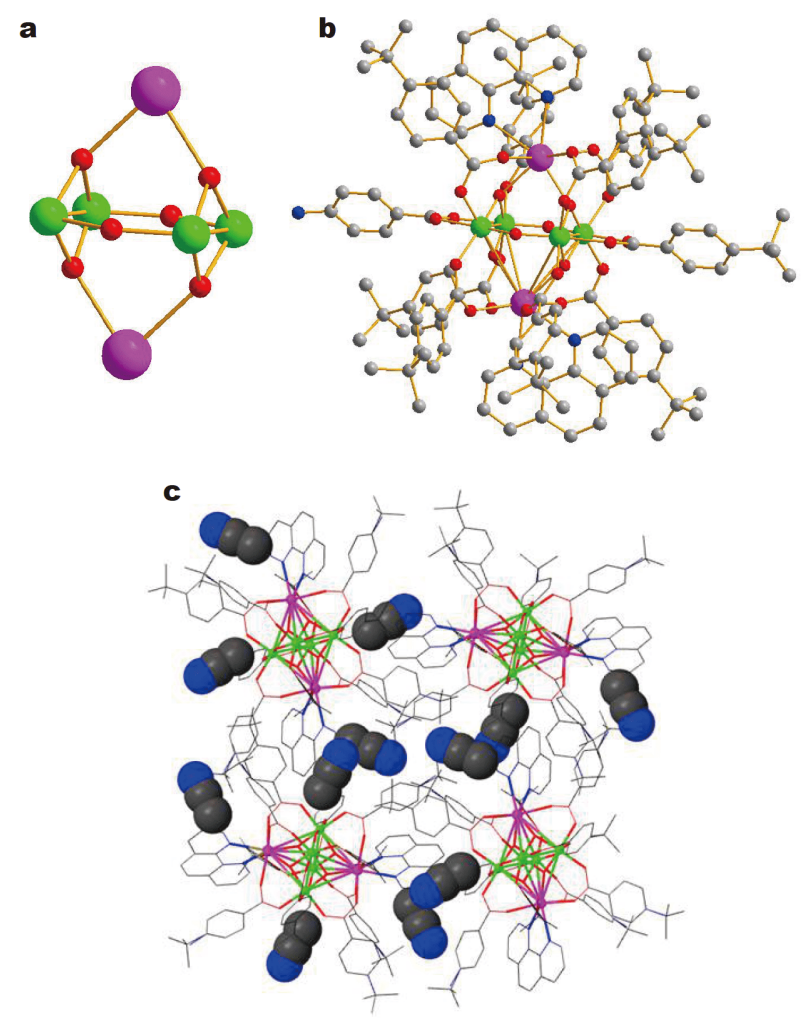

Figure 1 The metal core structure of 1 (a) and its coordination structure (b); the schematic diagram of the acetonitrile molecules in the single crystal structure in $\mathbf{1}$ (c). Color code: purple for $\mathrm{Eu}$, green for $\mathrm{Ti}$, red for $\mathrm{O}$, gray for $\mathrm{C}$, blue for $\mathrm{N}$. Hydrogen atoms are omitted for clarity.



Figure $2{ }^{1} \mathrm{H}$ NMR $\left(500 \mathrm{MHz}, \mathrm{CDCl}_{3}\right)$ spectra for PEG, 1 and 2.

These results imply that $\mathbf{1}$ is intact in $\mathbf{2}$. According to the elemental analysis of $\mathbf{2}$, the molecular weight of $\mathbf{2}$ is approximately $4400 \mathrm{~g} \mathrm{~mol}^{-1}$. Thus, the average ratio of 1 to PEG in $\mathbf{2}$ is $1 / 1$, consistent with the TG analysis of 2 (Fig. S2) and the crystal structure of $\mathbf{1}$. 



Figure 3 The excitation and emission spectra of 1 (a) and 2 (b) in the solid state. The insets are photographs of 1 and 2 under 312 nm UV irradiation (top) and in daylight (bottom). (c) Luminescence spectra of 2 in different solutions. (d) SEM images of 1 (left) and 2 (right) on the silicon substrate when the toluene solution was evaporated. (e) Images of 2 dissolved in different solvents under 312 -nm UV irradiation. MeCN: methyl cyanide, PhMe: toluene, THF: tetrahydrofuran, AcOEt: ethyl acetate, MeOH: methanol, DMF: N,N-dimethylformamide, EtOH: ethanol.

Fig. 3 shows the excitation and emission spectra of 1 and $\mathbf{2}$ in the solid-state. The peaks mainly appear in the ultraviolet (UV) region from 240 to $400 \mathrm{~nm}$, and the most intense signals in the excitation spectra for $\mathbf{1}$ and $\mathbf{2}$ are at 294 and 299 nm, respectively. As shown in Fig. 3a, b, both 1 and 2 display five $\mathrm{Eu}^{3+}$ emission peaks. The five $\mathrm{Eu}^{3+}$ emission peaks are at $577-581 \mathrm{~nm} \quad\left({ }^{5} \mathrm{D}_{0} \rightarrow{ }^{7} \mathrm{~F}_{0}\right)$, $585-602 \mathrm{~nm} \quad\left({ }^{5} \mathrm{D}_{0} \rightarrow{ }^{7} \mathrm{~F}_{1}\right), \quad 609-629 \mathrm{~nm} \quad\left({ }^{5} \mathrm{D}_{0} \rightarrow{ }^{7} \mathrm{~F}_{2}\right)$, $649-658 \mathrm{~nm} \quad\left({ }^{5} \mathrm{D}_{0} \rightarrow{ }^{7} \mathrm{~F}_{3}\right)$, and $685-708 \mathrm{~nm} \quad\left({ }^{5} \mathrm{D}_{0} \rightarrow{ }^{7} \mathrm{~F}_{4}\right)$, while those for 2 are at $577-581 \mathrm{~nm} \quad\left({ }^{5} \mathrm{D}_{0} \rightarrow{ }^{7} \mathrm{~F}_{0}\right)$, $586-601 \mathrm{~nm} \quad\left({ }^{5} \mathrm{D}_{0} \rightarrow{ }^{7} \mathrm{~F}_{1}\right), \quad 608-628 \mathrm{~nm} \quad\left({ }^{5} \mathrm{D}_{0} \rightarrow{ }^{7} \mathrm{~F}_{2}\right)$,
$647-658 \mathrm{~nm}\left({ }^{5} \mathrm{D}_{0} \rightarrow{ }^{7} \mathrm{~F}_{3}\right)$, and $680-708 \mathrm{~nm}\left({ }^{5} \mathrm{D}_{0} \rightarrow{ }^{7} \mathrm{~F}_{4}\right)$. The similarity between $\mathbf{1}$ and $\mathbf{2}$ in the excitation and emission spectra further suggests that $\mathbf{1}$ maintains its structural integrity in $\mathbf{2}$.

Table S3 shows the luminescence lifetime and quantum yield (QY) of $\mathbf{1}$ and $\mathbf{2}$ in the solid-state and solution, respectively. The solid-state lifetime and QY for $\mathbf{1}$ are $1643 \mu$ s and $50.91 \%$, respectively, while those for 2 are $1370 \mu$ s and $30.69 \%$, respectively (Figs S4 and S5). The difference in luminescence performance between $\mathbf{1}$ and $\mathbf{2}$ is attributed to the nonradiative vibration from PEG in $\mathbf{2}$ 

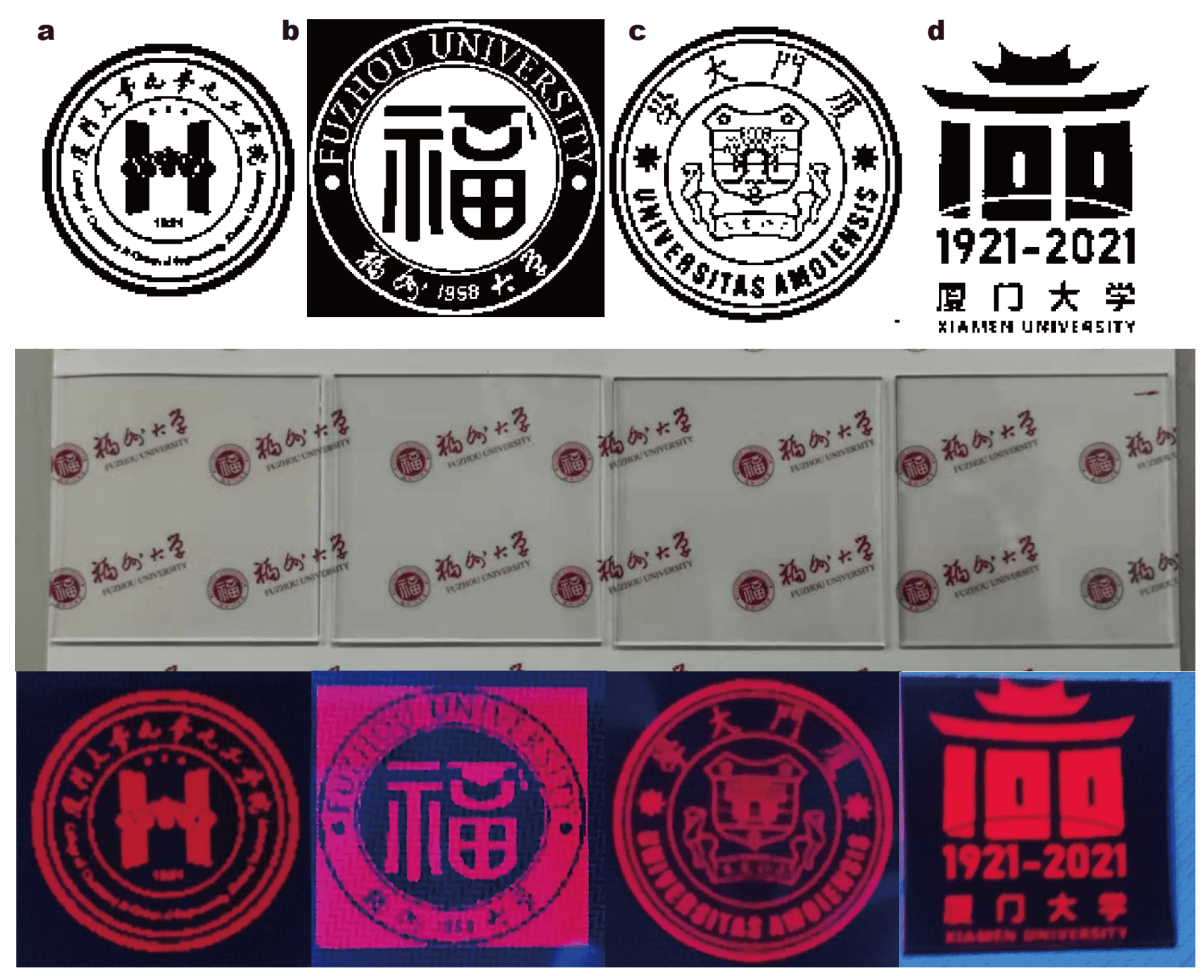

Figure 4 Images of the logos inkjet printed by 2 . The top images show input patterns. The middle images show the printed output patterns under daylight. The bottom images show printed output patterns under $312 \mathrm{~nm}$ UV light. (a) College of Chemistry and Chemical Engineering, Xiamen University logo; (b) Fuzhou University logo; (c) Xiamen University logo; (d) Xiamen University 100 centenary celebration logo.

[31]. Significantly, in comparison with $\mathbf{1}$, not only the solubility of $\mathbf{2}$ in polar solvents but also its adhesion to the substrate is obviously improved. As shown in Fig. 3, 2 can be dissolved in toluene, $\mathrm{CH}_{2} \mathrm{Cl}_{2}$, ethanol, ethyl acetate, etc., although the QYs of $\mathbf{2}$ in different solutions change on a case-by-case basis due to the solvent effects (Fig. 3c and Table S3). Moreover, scanning electron microscopy (SEM) images show that $\mathbf{1}$ exhibits obvious agglomerations and cracks, while $\mathbf{2}$ displays good film forming characteristics and adhesion to the substrate upon evaporation of the toluene solution (Fig. 3d).

Because $\mathbf{2}$ is stable in solution and has excellent film forming characteristics and strong fluorescence intensity, it was used to prepare the precursor ink for inkjet printing in a mixed solution of ethanol and ethylene glycol $(v / v=4 / 1)$. Such an ink is transparent and stable in the ambient environment, and the solvents have low toxicity, which is of great importance for industrialization. As shown in Fig. 4, when ink of 2 was used to print computer-designed logos on indium tin oxide (ITO) glass through a high-precision printer, the printed logos were transparent and invisible under ambient conditions (middle) due to the excellent film forming properties of $\mathbf{2}$. Upon irradiation with UV light, the printed logos exhibited bright red photoluminescence observed by the naked eye (bottom). It was mentioned that the anticounterfeiting labels printed by 2 remain bright after being exposed to the air for six months, which is comparable to that observed in CdS quantum dots (QDs) [11] and indicates that $\mathbf{2}$ has high light stability $[5,17]$ (Fig. S6). Therefore, 2, as a fluorescent ink, has both good concealment and effectiveness. These results indicate that the prepared materials hold promising potential in applications such as anticounterfeiting labels.

In summary, a lanthanide-polymer composite of $\mathbf{2}$ was, for the first time, prepared through the NHS-activated amidation reaction of $\mathbf{1}$ with PEG. Analysis of the ${ }^{1} \mathrm{H}$ NMR and SEM of $\mathbf{1}$ and $\mathbf{2}$ indicate that $\mathbf{1}$ is intact within 2. Significantly, when $\mathbf{2}$ was used to prepare the precursor ink for inkjet printing in a mixed solution of ethanol and ethylene glycol $(v / v=4 / 1)$, the printed logos displayed good concealment and effectiveness due to their excellent solubility in polar solvents, film formation and luminescent performance. Thus, $\mathbf{2}$, as a fluorescent ink, has the 
advantages of environmental friendliness, stability, good viscosity and excellent luminescent performance.

Received 28 April 2021; accepted 24 May 2021; published online 27 July 2021

1 Kelesidis T, Falagas ME. Substandard/counterfeit antimicrobial drugs. Clin Microbiol Rev, 2015, 28: 443-464

2 Singh $\mathrm{M}$, Haverinen HM, Dhagat $\mathrm{P}$, et al. Inkjet printing-process and its applications. Adv Mater, 2010, 22: 673-685

3 Gao Z, Han Y, Wang F. Cooperative supramolecular polymers with anthracene-endoperoxide photo-switching for fluorescent anti-counterfeiting. Nat Commun, 2018, 9: 3977

4 Carro-Temboury MR, Arppe R, Vosch T, et al. An optical authentication system based on imaging of excitation-selected lanthanide luminescence. Sci Adv, 2018, 4: e1701384

5 Liu Y, Zhou L, Li Y, et al. Highly fluorescent nitrogen-doped carbon dots with excellent thermal and photo stability applied as invisible ink for loading important information and anti-counterfeiting. Nanoscale, 2017, 9: 491-496

6 Jiang K, Zhang L, Lu J, et al. Triple-mode emission of carbon dots: Applications for advanced anti-counterfeiting. Angew Chem Int Ed, 2016, 55: 7231-7235

7 Li W, Zhang H, Zheng Y, et al. Multifunctional carbon dots for highly luminescent orange-emissive cellulose based composite phosphor construction and plant tissue imaging. Nanoscale, 2017, 9: $12976-12983$

8 Saraf M, Kumar P, Kedawat G, et al. Probing highly luminescent europium-doped lanthanum orthophosphate nanorods for strategic applications. Inorg Chem, 2015, 54: 2616-2625

9 Zhang Y, Zhang L, Deng R, et al. Multicolor barcoding in a single upconversion crystal. J Am Chem Soc, 2014, 136: 4893-4896

10 Han Y, Li H, Wang Y, et al. Upconversion modulation through pulsed laser excitation for anti-counterfeiting. Sci Rep, 2017, 7: 1320

11 Liu Y, Han F, Li F, et al. Inkjet-printed unclonable quantum dot fluorescent anti-counterfeiting labels with artificial intelligence authentication. Nat Commun, 2019, 10: 2409

12 Gao A, Yan J, Wang Z, et al. Printable $\mathrm{CsPbBr}_{3}$ perovskite quantum dot ink for coffee ring-free fluorescent microarrays using inkjet printing. Nanoscale, 2020, 12: 2569-2577

13 Jiang C, Zhong Z, Liu B, et al. Coffee-ring-free quantum dot thin film using inkjet printing from a mixed-solvent system on modified $\mathrm{ZnO}$ transport layer for light-emitting devices. ACS Appl Mater Interfaces, 2016, 8: 26162-26168

14 Pham H, Gourevich I, Oh J, et al. A multidye nanostructured material for optical data storage and security data encryption. Adv Mater, 2004, 16: 516-520

15 Kalita A, Malik AH, Sarma NS. Stimuli-responsive naphthalene diimide as invisible ink: A rewritable fluorescent platform for anticounterfeiting. Chem Asian J, 2020, 15: 1074-1080

16 Luo X, Li J, Li C, et al. Reversible switching of the emission of diphenyldibenzofulvenes by thermal and mechanical stimuli. Adv Mater, 2011, 23: 3261-3265

17 Wang YM, Tian XT, Zhang H, et al. Anticounterfeiting quick response code with emission color of invisible metal-organic frameworks as encoding information. ACS Appl Mater Interfaces, 2018, 10: $22445-22452$

18 Ou Y, Zhou W, Zhu Z, et al. Host differential sensitization toward color/lifetime-tuned lanthanide coordination polymers for optical multiplexing. Angew Chem Int Ed, 2020, 59: 23810-23816

19 Liu J, Zhuang Y, Wang L, et al. Achieving multicolor long-lived luminescence in dye-encapsulated metal-organic frameworks and its application to anticounterfeiting stamps. ACS Appl Mater Interfaces, 2018, 10: 1802-1809

20 Zhang HB, Liu M, Lei X, et al. Digital controlled luminescent emission via patterned deposition of lanthanide coordination compounds. ACS Appl Mater Interfaces, 2014, 6: 12594-12599

21 Andres J, Hersch RD, Moser JE, et al. A new anti-counterfeiting feature relying on invisible luminescent full color images printed with lanthanide-based inks. Adv Funct Mater, 2014, 24: 5029-5036

22 Wang JJ, Chen C, Chen WG, et al. Highly luminescent copper iodide cluster based inks with photoluminescence quantum efficiency exceeding 98\%. J Am Chem Soc, 2020, 142: 3686-3690

23 Gálico DA, Kitos AA, Ovens JS, et al. Lanthanide-based molecular cluster-aggregates: Optical barcoding and white-light emission with nanosized $\left\{\operatorname{Ln}_{20}\right\}$ compounds. Angew Chem Int Ed, 2021, 60: 6130-6136

24 Liu YJ, Fang WH, Zhang L, et al. Recent advances in heterometallic polyoxotitanium clusters. Coord Chem Rev, 2020, 404: 213099

25 Li N, Subramanian GS, Matthews PD, et al. Energy transfer and photoluminescence properties of lanthanide-containing polyoxotitanate cages coordinated by salicylate ligands. Dalton Trans, 2018, 47: 5679-5686

26 Lv Y, Cai Z, Yan D, et al. Novel Eu-containing titania composites derived from a new $\mathrm{Eu}(\mathrm{III})$-doped polyoxotitanate cage. RSC Adv, 2016, 6: 57-60

27 Chen R, Hong ZF, Zhao YR, et al. Ligand-dependent luminescence properties of lanthanide-titanium oxo clusters. Inorg Chem, 2019, 58: 15008-15012

28 Zhao YR, Zheng H, Chen LQ, et al. The effect on the luminescent properties in lanthanide-titanium oxo clusters. Inorg Chem, 2019, 58: $10078-10083$

29 Deng YK, Zhao YR, Xu H, et al. Preparation of a lanthanidetitanium oxo cluster-polymer composite by $\mathrm{Cu}^{\mathrm{I}}$-catalyzed click chemistry. Chem Eur J, 2021, 27: 614-617

30 Zheng H, Deng YK, Ye MY, et al. Lanthanide-titanium oxo clusters as the luminescence sensor for nitrobenzene detection. Inorg Chem, 2020, 59: 12404-12409

31 Li SPY, Lau CTS, Louie MW, et al. Mitochondria-targeting cyclometalated iridium(III)-PEG complexes with tunable photodynamic activity. Biomaterials, 2013, 34: 7519-7532

Acknowledgements This work was supported by the National Natural Science Foundation of China (21673184 and 21721001).

Author contributions Long L initiated and coordinated the research. Deng Y synthesized the materials, conducted the measurements and wrote the manuscript draft. Zheng $X$ printed the anticounterfeiting labels. Zheng $\mathrm{H}$ conducted the fluorescence test. $\mathrm{Xu} \mathrm{H}$ conducted the SCXRD characterization and solved the crystallographic structure. Li F, Long $\mathrm{L}$, Zheng $\mathrm{L}$ participated in the discussion and analysis of the data.

Conflict of interest The authors declare that they have no conflict of interest.

Supplementary information Experimental details and supporting data are available in the online version of the paper. 




Yongkai Deng received his BSc degree from Shandong University (2015). He is now a PhD student at the College of Chemistry and Chemical Engineering, Xiamen University, under Prof. Lasheng Long's supervision. His research topic is metal cluster-polymer composites.

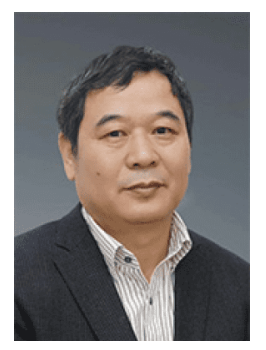

Lasheng Long received his BSc degree from Anhui Normal University (1986). He completed his PhD degree at Sun Yat-sen University (1999). He was a visiting associate professor at the Institute of Molecular Sciences, Japan (2005-2006). $\mathrm{He}$ is now a professor in the Department of Chemistry at Xiamen University. His current research interests include the synthetic protocol, structure and magnetocaloric effect of lanthanide-transition metal clusters, inorganic-organic hybrid molecular multiferroic, and magnetoelectric materials.

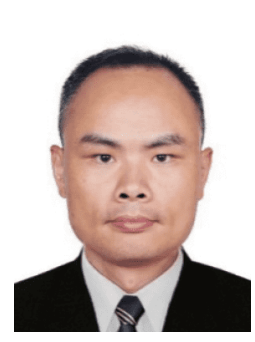

Fushan Li received his $\mathrm{PhD}$ degree from Peking University in 2005 . He was a research professor at Hanyang University of Korea in 2007, and a research fellow at Nanyang Technological University in 2010. Now he is a full professor at Fuzhou University in China. His research mainly focuses on the nano-optoelectronic devices utilizing semiconductor nanoparticles, carbonbased nanomaterials and novel $2 \mathrm{D}$ atomic crystals.

\section{稀土钝氧簇-高分子复合材料：从簇合物到苂光油} 墨

邓永恺 ${ }^{1}$, 郑釒 ${ }^{2}$, 郑浩 $^{1}$, 徐寒 ${ }^{1}$, 李福山 ${ }^{2^{*}}$, 龙腊生 ${ }^{1^{*}}$, 郑兰称 ${ }^{1}$

摘要 要将荧光油墨应用于实际, 通常要求该油墨对环境友好且稳 定, 并且具有良好的黏度和优异的发光性能. 本文中, 我们通过含有 氨基的稀土钛氧簮 $\mathrm{Eu}_{2} \mathrm{Ti}_{4}-\mathrm{NH}_{2}(\mathbf{1})$ 与 $\mathrm{PEG}(\mathrm{PEG}=$ 甲氧基聚乙二醇 琥珀酰亚胺碳酸酯, $2000 \mathrm{~g} \mathrm{~mol}^{-1}$ ) 反应合成了稀土钛氧簇-高分子 复合材料 $\mathrm{Eu}_{2} \mathrm{Ti}_{4}-\mathrm{NH}_{2} @$ PEG (2). 对 2 的相关表征表明, 1 的结构在 2 之内是完整的. 1 和 $\mathbf{2}$ 的发光性质表明其固态量子产率分别为 $50.91 \%$ 和 $30.69 \%$. 与化合物 $\mathbf{1}$ 相比, 2 在极性溶剂中的溶解度和成膜 性能大大提高. 当使用 $\mathbf{2}$ 的乙醇/乙二醇 $(v / v=4 / 1)$ 混合溶液用于喷 墨打印的墨水时, 喷墨打印的标签显示出良好的隐蔽性和有效性. 